\title{
Symptomatic large or giant capillary telangiectasias: management and outcome in 5 cases
}

\author{
*Tao Yu, MD, ${ }^{1}$ Xingwen Sun, MD, ${ }^{1}$ Yan You, MD, ${ }^{2}$ Jie Chen, MD, ${ }^{2}$ Jun-mei Wang, MD, ${ }^{3,4}$ \\ Shuo Wang, MD, ${ }^{1}$ Ning Lin, MD, ${ }^{5}$ Buqing Liang, MD, ${ }^{6}$ and Jizong Zhao, MD ${ }^{1}$

\begin{abstract}
Departments of ${ }^{1}$ Neurosurgery and ${ }^{3}$ Pathology, Beijing Tiantan Hospital, Capital Medical University; ${ }^{2}$ Department of Pathology, Peking Union Medical College Hospital; and ${ }^{4}$ Department of Neuropathology, Beijing Neurosurgical Institute, Beijing, China; ${ }^{5}$ Department of Neurological Surgery, NewYork-Presbyterian Hospital/Weill Cornell Medical College, New York; and ${ }^{6}$ Department of General Surgery, Harlem Hospital, Columbia University Medical Center, New York, New York
\end{abstract}

Brain capillary telangiectasias (BCTs) are usually small and benign with a predilection in the pons and basal ganglion. Reports of large and symptomatic BCTs are rare. Large BCTs have a much higher risk of causing uncontrolled bleeding and severe neurological defects, and they can be fatal if left untreated. Therefore, large BCTs should be managed with special caution. Because of the lack of reports, diagnosis of large BCTs has been difficult. Strategies of management are undefined for large or giant BCTs.

The current study presents 5 cases of giant and large BCTs. To the authors' knowledge, this is the largest series of this disease ever reported. Radiological findings, histopathological characteristics, clinical presentations, and surgical management were analyzed in 5 symptomatic, unusually large BCTs (mean diameter $5.06 \mathrm{~cm}$, range $1.8-8 \mathrm{~cm}$ ).

Four patients presented with focal or generalized seizures, and 1 patient presented with transient vision loss attributed to the lesions. Gross-total resection of the lesion was achieved in all patients. After surgery, the 4 patients with seizures were symptom free for follow-up periods varying from more than 1 to 5 years with no additional neurological deficits.

The unique location, radiological characteristics, and clinical course suggest that giant BCTs could be a different entity from small BCTs. Surgery might be a good option for treatment of patients with intractable neurological symptoms, especially in those with surgically accessible locations. Complete removal would be anticipated to provide relief of the symptoms without causing new neurological deficits.

http://thejns.org/doi/abs/10.3171/2015.5.JNS142805

KEY WORDS capillary telangiectasia; vascular malformation; resection; vascular disorders

$\mathrm{B}$ RAIN capillary telangiectasia (BCT) is a rare vascular malformation with a prevalence of $0.4 \%-0.7 \%$ based on autopsy and MRI diagnosis. ${ }^{12}$ Most BCTs are small in size and clinically silent with a predilection of pons and basal ganglia. Clinical data of large and symptomatic BCTs are rare. Only 10 symptomatic cases with 3 diffuse BCTs have been reported in the English-language literature of more than 200 BCTs..$^{12,20,24,27,29}$ Large BCTs have a much higher risk of causing uncontrolled bleeding and severe neurological deficits and even death if left untreat-

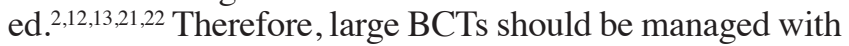
special caution. Due to their rarity, the diagnosis of large
BCTs has been difficult..$^{29,30}$ Large BCTs have different radiological characteristics, histopathological characteristics, and clinical courses from small BCTs. ${ }^{8,12,25}$ Standard management is undefined for large or giant BCTs. ${ }^{7,12,20,24,27,29}$ To our knowledge, the current study presents the largest case series of large BCTs ever reported. We analyzed the radiological findings, histopathological characteristics, clinical presentation, and management in 5 symptomatic, unusually large BCTs (mean diameter $5.06 \mathrm{~cm}$, range $1.8-8 \mathrm{~cm}$ ). Coexisting cavernous malformations (CMs) were confirmed in 3 cases. Resections were performed in all patients to control seizures and other recurrent neurological events.

ABBREVIATIONS BCT = brain capillary telangiectasia; $\mathrm{CM}=$ cavernous malformation; $\mathrm{DSA}=$ digital subtraction angiography; ECoG = electrocorticography; EEG = electroencephalography.

SUBMITTED December 9, 2014. ACCEPTED May 14, 2015.

INCLUDE WHEN CITING Published online November 13, 2015; DOI: 10.3171/2015.5.JNS142805.

* Drs. Yu and Sun contributed equally to this work. 


\section{Methods}

This study was approved by the local ethics board. Informed consent was obtained from all patients. All 5 cases were histologically confirmed as BCTs according to WHO classification. The review of these specimens was performed by 2 neuropathologists from Peking Union Medical College Hospital. There were 4 males and 1 female with a median age of 18 years (range 3-35 years) who presented with symptoms including seizures (4 cases) and recurrent neurological event (1 case). The time delay between the first symptoms and diagnosis was 1 month to 3 years; $1.5-\mathrm{T}$ or 3-T T1-weighted and T2-weighted images were obtained in all cases. The maximum diameters of the lesions varied from 1.8 to $8 \mathrm{~cm}$ (Table 1). T1weighted MRI after gadolinium contrast administration was performed in 2 cases (Cases 1 and 4). Digital subtraction angiography (DSA) was performed in 3 cases (Cases 1,3 , and 5), and MR angiography was performed in 1 case (Case 2). Preoperative interictal electroencephalography (EEG) and intraoperative electrocorticography (ECoG) were performed to localize and monitor the epileptic focuses before and during the surgeries. The mean follow-up time was $23 \pm 15$ months $( \pm \mathrm{SD})$.

\section{Results \\ Case 1}

An 8-year-old boy presented with 3 years of recurrent status epilepticus with binocular right-sided lateral gaze accompanied by nausea and vomiting. Management of seizures with oral valproate sodium reduced seizure frequency. However, side effects of valproate sodium involving gastrointestinal distress progressed, and patient compliance was poor. The patient still experienced 1 seizure episode each week while receiving medication. Left frontal focal sharp waves were found on EEG, indicating potential seizure focus, which was consistent with the location of the lesion. Brain MRI showed a cone-shaped lesion measuring $6.5 \times 5.0 \mathrm{~cm}$ in the left frontal lobe. The lesion was slightly hypointense on T1-weighted MRI and hyperintense on T2-weighted MRI. After contrast administration, the lesion demonstrated linear enhancement on the surface, suggesting engorged draining veins (Fig. 1). The lesion was first diagnosed as either an undefined vascular malformation or a dysembryoplastic neuroepithelial tumor.

Resection was scheduled for suspected neoplastic lesion associated with seizure. After complete resection, the preoperatively observed epileptiform abnormalities on EEG vanished on intraoperative ECoG monitoring. The histopathological examination showed cortical neural tissue with numerous intervening dilated capillaries, which was consistent with capillary telangiectasias. Areas of CM with tightly compacted vessels were also detected (Fig. 1). The patient's postoperative course was uneventful. As of the last follow-up (4 years after surgery), conservative management was terminated for more than 1 year. The patient's mental development was age appropriate, and his school performance was unchanged compared with before surgery.

\section{Case 2}

A 3-year-old girl presented with generalized tonicclonic seizures precipitated by diffuse abdominal pain, nausea, and vomiting. The initial seizure onset occurred 1 month prior to presentation. The patient experienced 4 episodes of seizure within that month, which could not be controlled by antiepileptic agents. Preoperative brain T1- and T2-weighted images showed a cone-shaped lesion with a brushlike vascular structure that measured $8.0 \times$ $3.0 \mathrm{~cm}$ in the right temporooccipital region. Within the lesion, there were small hypointense and hyperintense nodules indicating hemorrhagic foci (Fig. 2). The MR angiography study did not show any vascular malformation. EEG revealed a slow wave at the right temporooccipital region, although no typical epileptic wave was detected. Resection was scheduled for seizure control.

The lesion was totally removed in a piecemeal fashion. The amount of blood loss was $200 \mathrm{ml}$. Histopathological examination showed cortical neural tissue with significantly increased numbers of dilated capillary-type blood vessels, consistent with capillary telangiectasias (Fig. 2). The patient recovered well from the surgery and was discharged on antiepileptic drugs. She stopped taking medications 5 months before the last follow-up (12 months after surgery) and did not experience any further seizure episodes.

\section{Case 3}

A 17-year-old man presented with right-sided complex partial seizures. During the seizure episode, the patient experienced right-sided facial spasm, myoclonic movement of the right extremities with his head turning to the right, and bilateral upward eye deviation. Antiepileptic medications including valproic acid, lamotrigine, and carbamazepine were administered each for 4-6 months as initial

TABLE 1. Characteristics of 5 patients with large or giant capillary telangiectasias

\begin{tabular}{cccccccc}
\hline $\begin{array}{c}\text { Case } \\
\text { No. }\end{array}$ & $\begin{array}{c}\text { Age }(\mathrm{yrs}), \\
\text { Sex }\end{array}$ & Size $(\mathrm{cm})$ & \multicolumn{1}{c}{ Location } & Symptoms & \multicolumn{1}{c}{ DSA } & $\begin{array}{c}\text { Dilated } \\
\text { Draining Vein }\end{array}$ & Pathology \\
\hline 1 & $8, \mathrm{M}$ & $6.5 \times 5.0$ & Lt frontal lobe & Seizure & No positive finding & Yes & Mixed BCT \& CM \\
\hline 2 & $3, \mathrm{~F}$ & $8.0 \times 3.0$ & $\begin{array}{c}\text { Rt temporooccipital } \\
\text { region }\end{array}$ & Seizure & Not performed & Yes & BCT \\
\hline 3 & $17, \mathrm{M}$ & $5.0 \times 4.0$ & Lt frontal lobe & Seizure & No positive finding & Yes & Mixed BCT \& CM \\
\hline 4 & $35, \mathrm{M}$ & $1.8 \times 1.3$ & Lt temporal lobe & $\begin{array}{c}\text { Lt eye transient } \\
\text { vision loss }\end{array}$ & Not performed & No & $\begin{array}{c}\text { Intermittent form of } \\
\text { BCT \& CM }\end{array}$ \\
\hline 5 & $19, \mathrm{M}$ & $4.0 \times 3.0$ & Rt temporal lobe & Seizure & No positive finding & Yes & Mixed BCT \& CM \\
\hline
\end{tabular}



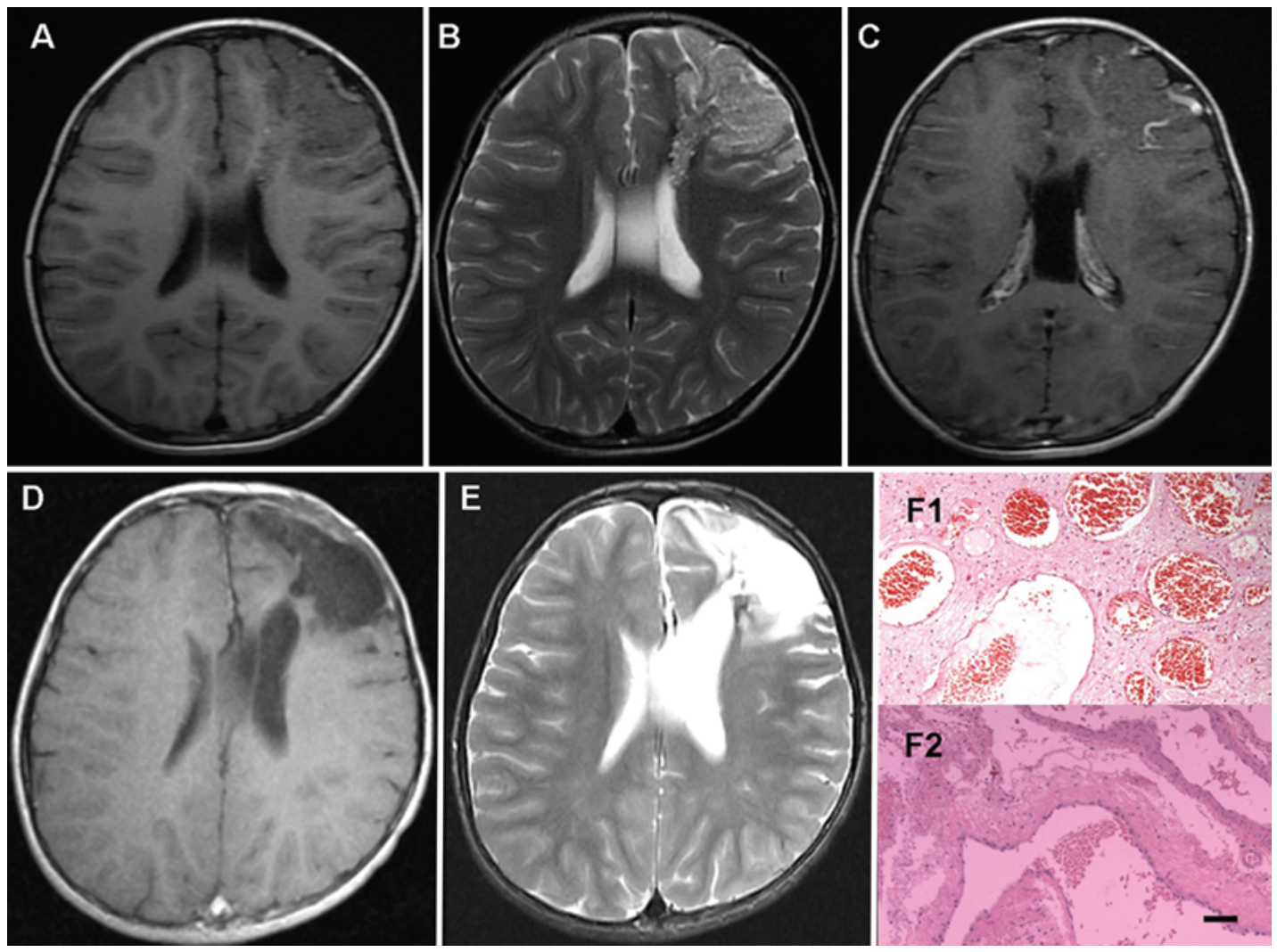

FIG. 1. Case 1. Axial T1-weighted (A) and T2-weighted (B) images demonstrating an isointense cone-shaped lesion in the left frontal lobe. Gadolinium-enhanced T1-weighted image (C) revealing moderate linear enhancing vessels on the surface of the lesion, suggesting dilated draining veins. Postoperative T1-weighted (D) and T2-weighted (E) MR images. Dilated vessel walls with interspersed neuronal tissue are observed on light microscopic examination of the lesion (F1). A coexisting CM within the lesion is confirmed on histopathological study (F2). $\mathrm{H} \& \mathrm{E}$, original magnification $\times 100$; bar $=100 \mu \mathrm{m}$. Figure is available in color online only.

therapy. Although the frequency of the seizure episodes was reduced, none of the drugs was able to completely eliminate the seizure. The left frontal lesion measured 5.0 $\times 4.0 \mathrm{~cm}$ (Fig. 3) and was diagnosed as being either a vascular malformation or low-grade glioma. EEG detected bilateral frontoparietal epileptic waves with a left-sided dominance, which is consistent with the location of the vascular lesion. Surgery was scheduled for resection of a suspected vascular malformation/neoplastic lesion associated with intractable seizure.

During the operation, the preoperative visible ECoG spike wave at the left frontal lobe disappeared after resection of the mass. The histopathological evaluation of the lesion was consistent with capillary telangiectasias with coexisting venous malformation. The patient recovered well and has been seizure free since the most recent follow-up ( 2 years after surgery).

\section{Case 4}

A 35-year-old woman complaining of transient visual loss accompanied by dizziness for 3 weeks presented to our clinic. Ophthalmological examination findings were normal for both eyes. Brain MRI showed a lesion in the left mesial temporal lobe adjacent to the hippocampal head. The $1.8 \times 1.3-\mathrm{cm}$ lesion was mildly hypointense on T1-weighted images, isointense on T2-weighted images, and slightly enhanced after contrast administration (Fig. 4). Low-grade glioma was suggested as the initial diagnosis, and surgical removal was scheduled.

A gray-reddish mass with enriched blood supply located adjacent to the head of the hippocampus was completely removed in the surgery. The histopathological evaluation of the lesion demonstrated clusters of dilated capillaries (Fig. 4). This patient underwent follow-up for 5 years and 6 months; her vision improved gradually, and no additional neurological disability was observed.

\section{Case 5}

A 19-year-old man presented with recurrent generalized seizures induced by exhaustion. Preoperative brain MRI showed a vascular lesion measuring $4.0 \times 3.0 \mathrm{~cm}$ in the right temporal lobe; findings on DSA appeared normal (Fig. 5). Preoperative EEG demonstrated spike form discharge at the location of the lesion. The seizure was intractable with long-term anticonvulsant medication. A lesionectomy was performed. Postoperative imaging studies confirmed a gross-total resection. The histopathological examination of the lesion was consistent with capillary telangiectasias with a coexisting venous malformation (Fig. 5). The patient recovered well and at the most recent follow-up (1 year and 6 months after surgery) had not experienced any seizures. 

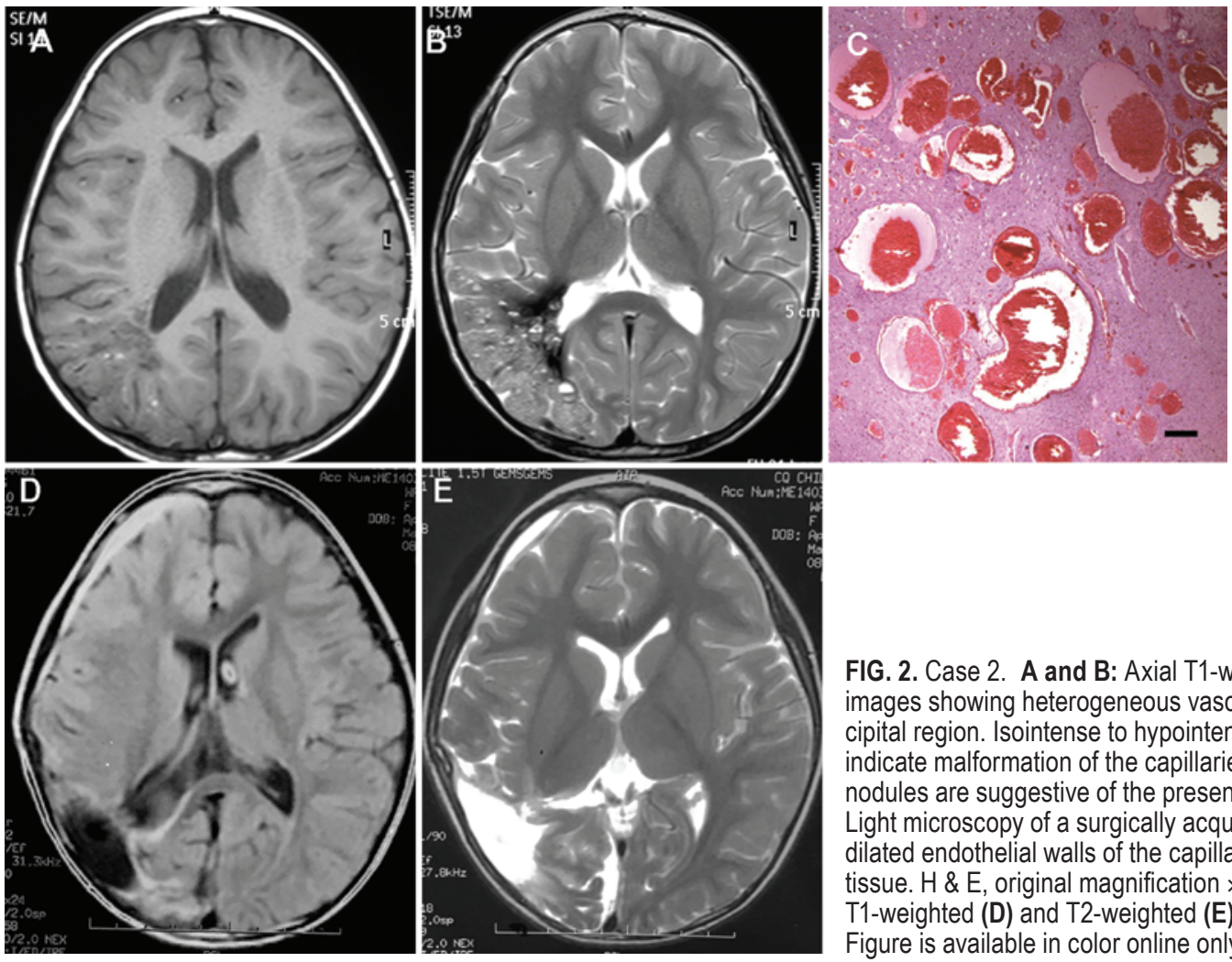

FIG. 2. Case 2. A and B: Axial T1-weighted (A) and T2-weighted (B) images showing heterogeneous vascular lesions of the right temporooccipital region. Isointense to hypointense brush-like patterns of the lesion indicate malformation of the capillaries. Hypointense and hyperintense nodules are suggestive of the presence of small hemorrhagic foci. C: Light microscopy of a surgically acquired sample demonstrating the dilated endothelial walls of the capillaries with intervening neuronal tissue. $\mathrm{H} \& \mathrm{E}$, original magnification $\times 100$; bar $=100 \mu \mathrm{m}$. Postoperative T1-weighted (D) and T2-weighted (E) images showing no residual tumor. Figure is available in color online only.
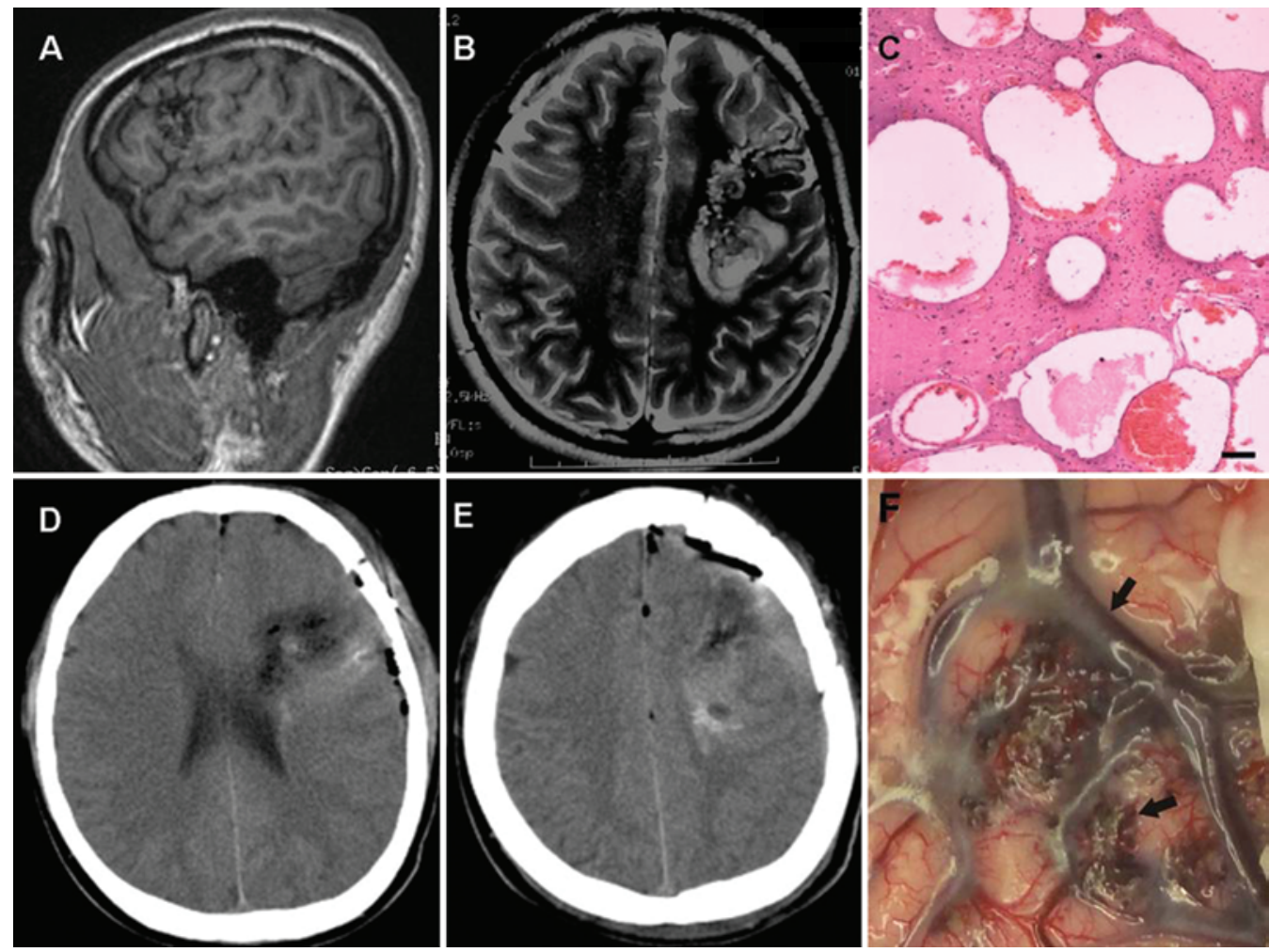

FIG. 3. Case 3. A and B: Sagittal T1-weighted (A) and axial T2-weighted (B) images showing vascular structure with no mass effect in the left frontal parietal lobe. The lesion is isointense on the T1-weighted image and heterogeneous on the T2-weighted image. Surrounding hypointensity of the lesion on the T1-weighted image suggests previous hemorrhage. Intervening brain parenchyma can be seen on the T2-weighted image. C: Light microscopic study revealing dilated capillary structure with intervening brain tissue. $\mathrm{H} \& \mathrm{E}$, original magnification $\times 100 ;$ bar $=100 \mu \mathrm{m}$. D and E: Postoperative CT scans showing no bleeding. F: Intraoperative photograph showing the vascular lesion (arrows). Figure is available in color online only. 

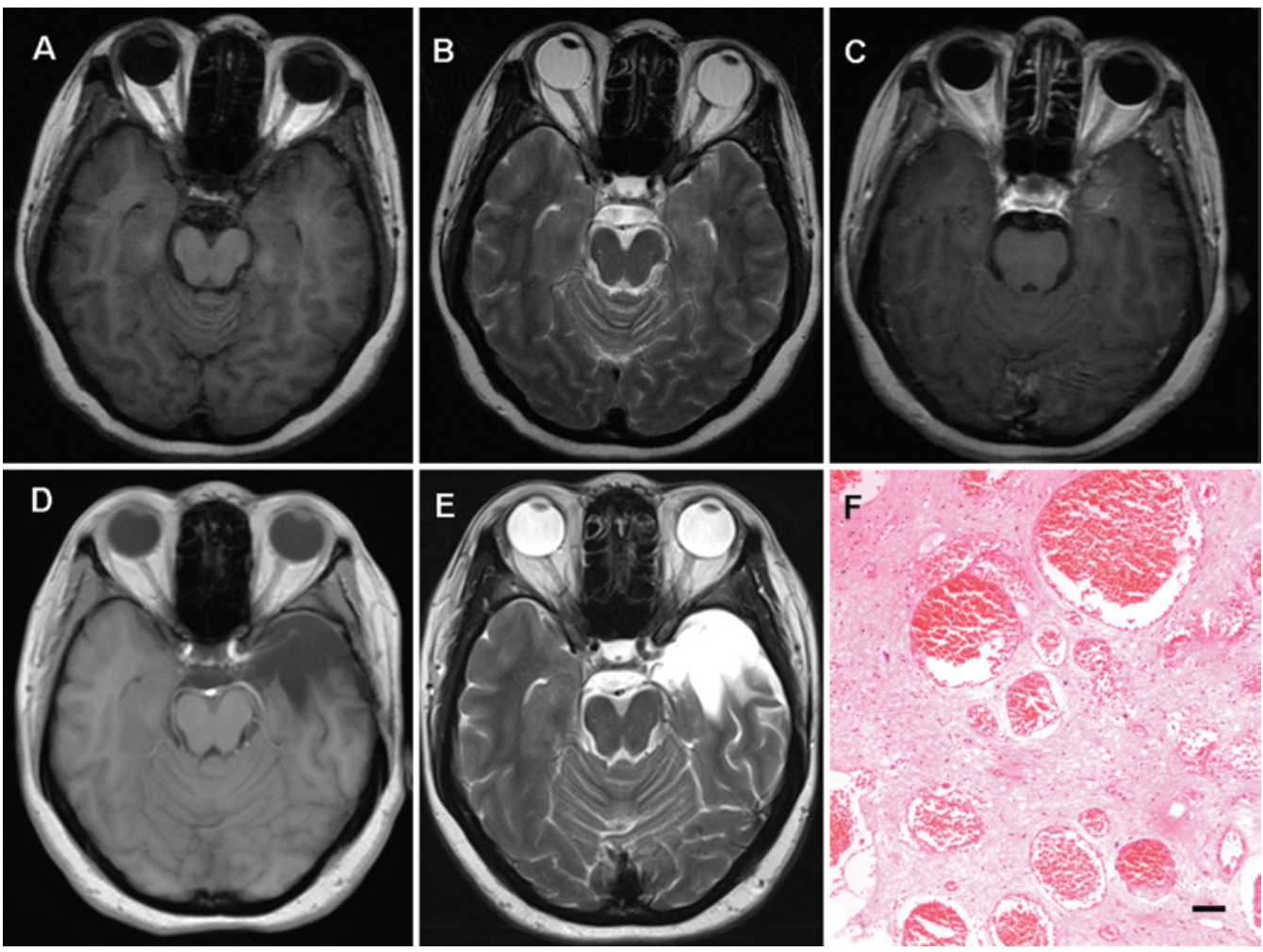

FIG. 4. Case 4. A and B: Axial T1-weighted (A) and T2-weighted (B) images showing a subtle isointense lesion within the left temporal lobe. C: Postcontrast T1-weighted image showing mild enhancement of the lesion with linear enhancement. D and E: Postoperative T1- and T2-weighted images. No residual lesion can be seen. F: Light microscopy showing the typical histopathological appearance of a BCT. H \& E, original magnification $\times 100$; bar $=100 \mu \mathrm{m}$. Figure is available in color online only.

\section{Discussion}

Most of the reported BCTs are small and clinically silent. ${ }^{12}$ Traditionally, invasive management had been avoided in small asymptomatic BCTs because of the high risk of hemorrhage. Nevertheless, recent studies revealed that untreated large or giant BCTs tend to have an aggressive course with hemorrhage, which might lead to permanent neurological deficits or even death. ${ }^{12,13,27,29}$ Conservative management might be insufficient to either prevent the progression or control the symptoms. In the previous literature, surgical management of giant and large BCTs has been reported to have favorable outcomes. ${ }^{4,6,17,18,22,24,25,27}$ In our case series, all lesions were symptomatic and their surgical removal lesions resulted in significant symptom relief.

\section{Diagnosis of BCTs}

Diagnosis of capillary telangiectasia is mainly based on location and radiological characteristics. ${ }^{3,9,10,12,16}$ Differentiating BCTs from other brain lesions such as infarction, neoplasm, and hemorrhage is challenging. ${ }^{16}$ Large BCTs have been frequently misdiagnosed. Precise identification of the lesion is critical for both diagnosis and management. $1,6,8,19,25,26$

Mild or moderate enhancement with irregular borders on contrast-administered T1-weighted imaging seems to be a common finding for both small and large BCTs. ${ }^{10,27}$ For small BCTs, T1- and T2-weighted images alone are oftentimes insufficient to establish a diagnosis, so that sus- ceptibility-weighted images and diffusion-weighted images are often required. ${ }^{5,7,10}$ In contrast, large BCTs can be visualized on T1- and T2-weighted images as the vessel abnormalities are quite prominent. ${ }^{9}$ After contrast administration, larger BCTs often demonstrate weblike linear enhancement with heterogeneously intense nodules. ${ }^{9}$ In our series, the lesions were visible on T1- and T2-weighted images in Cases 1 and 2, presenting as prominent brushlike cone-shaped lesions with linear enhancement accompanied by interspersed hypo- and hyperintense nodules. On T2-weighted images, a hypointense margin around the proximal part of the lesions was observed in 3 cases, suggestive of old hemorrhage or a coexisting CM. Dilated draining veins were observed in 4 of the 5 cases (80\%) in our series. ${ }^{7,12}$

Gross et al. proposed that there might be a stage in the formation between BCT and CM, which could be defined as a new entity. ${ }^{12}$ The unique characteristics of the giant BCTs in our series add more support to this theory. ${ }^{6,8,11}$ Small BCT and CM might be the two ends of the same pathological entity, with giant or large BCT as the bridging developmental stage. Moreover, it has been suggested that either BCT or CM could develop as a consequence of dynamic change in the blood flow and then develop into the other type of lesion (i.e., CM or BCT). ${ }^{12,23}$

\section{Histopathology of Large BCTs}

The histopathological characteristics of BCTs have been well described in previous studies. ${ }^{10,15,16,20}$ Micro- 

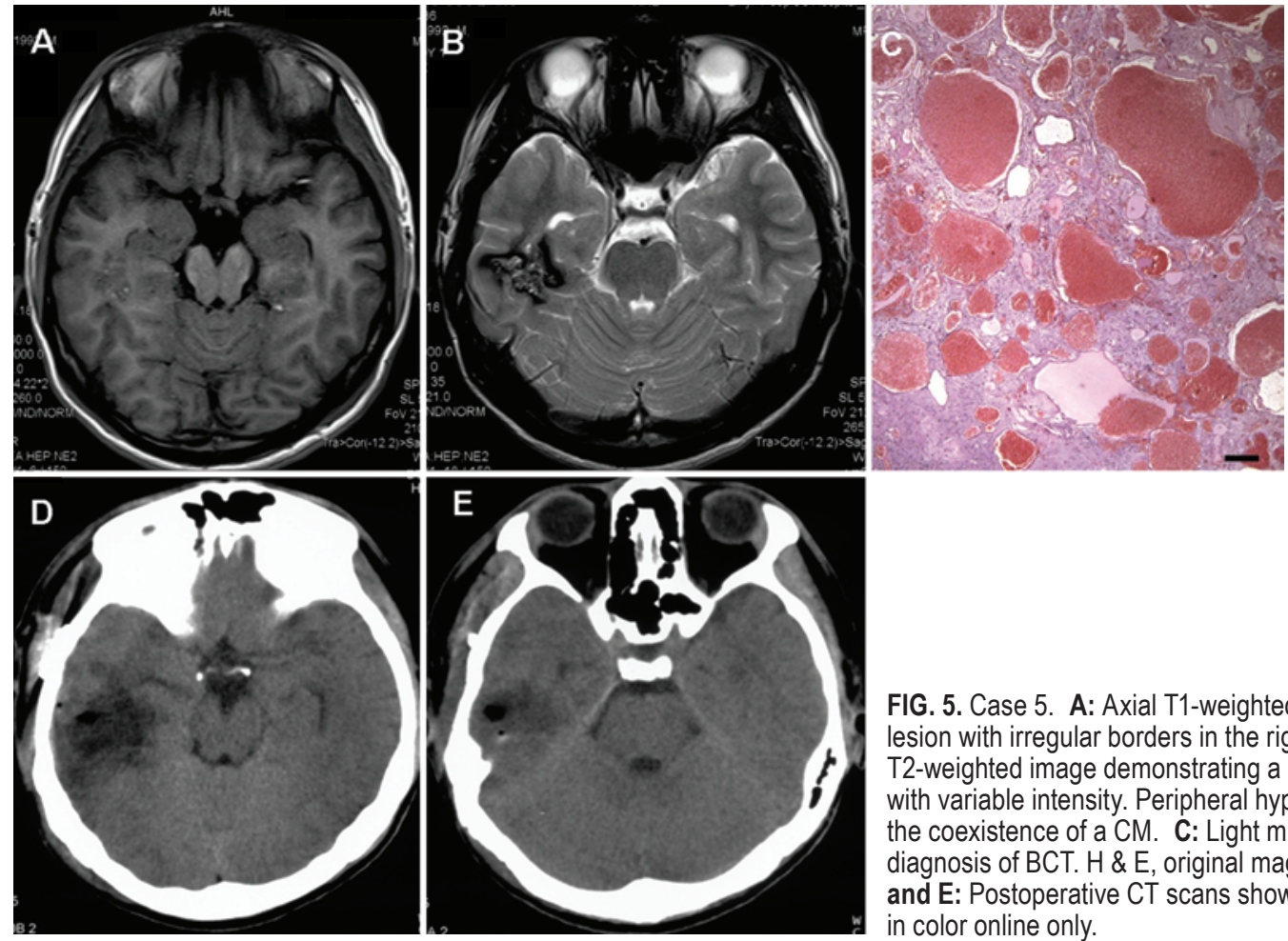

FIG. 5. Case 5. A: Axial T1-weighted image showing an isointense lesion with irregular borders in the right mesial temporal lobe. B: Axial T2-weighted image demonstrating a heterogeneously enhanced lesion with variable intensity. Peripheral hypointensity of the lesion suggested the coexistence of a CM. C: Light microscopic study confirmed the diagnosis of BCT. H \& E, original magnification $\times 100$; bar $=100 \mu \mathrm{m}$. D and E: Postoperative CT scans showing no bleeding. Figure is available in color online only.

scopically, BCTs are composed of numerous thin-walled, well-formed capillary vessels with interspersed normal neuronal tissue. The pathogenic relationships among $\mathrm{BCT}, \mathrm{CM}$, and developmental venous anomaly have been increasingly discussed. Both BCT and CM have been reported to have formed de novo with the presence of developmental venous anomaly. ${ }^{1,11}$ Restricted venous outflow may cause capillary hypertension and induce dilation of the vessel wall. Also, increased arterial perfusion caused by capillary dilation might lead to development of a venous anomaly. ${ }^{1,6}$ The presence of histopathological characteristics of BCT with radiological signs of CM observed in our series indicate BCT and CM might have the same pathological origin. In previous studies, it has been suggested that CM is a late stage of evolution of the BCT. ${ }^{13}$ In recent years, there have been increasing reports of mixed BCTs and CMs. ${ }^{25}$

\section{Treatment of Large or Giant BCTs}

For small asymptomatic lesions, conservative treatment is the first choice. ${ }^{15,16,28}$ However, unlike small BCTs, hypoperfusion of the involved region is more severe in large BCTs. ${ }^{12}$ Ischemic accident has been reported in previous studies. ${ }^{9,27,29}$ In addition, development of an aggressive form with increased risk of bleeding from giant or diffuse BCTs has also been reported..$^{24,29}$ In the existing reports of 10 cases of symptomatic large BCTs, 8 underwent resection. Favorable outcomes without significant neurological deficits were documented in most of these cases. ${ }^{4,6,14,17,18,24}$ In our series, patients with intractable seizures were seizure free, and the patient with episodic visual disturbances regained her vision gradually. Conservative therapy should be recommended after surgery to reach optimal control of the symptoms.

\section{Conclusions}

Large BCTs present with radiological, histopathological, demographic, and clinical features that are distinct from small BCTs. The frequently observed coexistence of $\mathrm{CM}$ indicates the existence of a form occurring between the stages of capillary and venous malformation. ${ }^{8,11,12}$ This entity should be managed in time to avoid severe sequelae as reported in previous studies., ${ }^{2,12,13,21,22}$ Surgery might offer a good option for treatment of patients with intractable neurological symptoms, especially when the location of the lesions is surgically accessible, and complete removal is expected to provide effective relief of the symptoms without causing new neurological deficits.

\section{References}

1. Abla A, Wait SD, Uschold T, Lekovic GP, Spetzler RF: Developmental venous anomaly, cavernous malformation, and capillary telangiectasia: spectrum of a single disease. Acta Neurochir (Wien) 150:487-489, 2008

2. Awad IA, Robinson JR Jr, Mohanty S, Estes ML: Mixed vascular malformations of the brain: clinical and pathogenetic considerations. Neurosurgery 33:179-188, 1993

3. Barr RM, Dillon WP, Wilson CB: Slow-flow vascular malformations of the pons: capillary telangiectasias? AJNR Am J Neuroradiol 17:71-78, 1996

4. Cantore G, Missori P, Santoro A: Cavernous angiomas of the brain stem. Intra-axial anatomical pitfalls and surgical strategies. Surg Neurol 52:84-94, 1999

5. Castillo M, Morrison T, Shaw JA, Bouldin TW: MR imaging and histologic features of capillary telangiectasia of the basal ganglia. AJNR Am J Neuroradiol 22:1553-1555, 2001

6. Chang SD, Steinberg GK, Rosario M, Crowley RS, Hevner RF: Mixed arteriovenous malformation and capillary telangiectasia: a rare subset of mixed vascular malformations. Case report. J Neurosurg 86:699-703, 1997 
7. Chaudhry US, De Bruin DE, Policeni BA: Susceptibilityweighted MR imaging: a better technique in the detection of capillary telangiectasia compared with $\mathrm{T} 2 *$ gradient-echo. AJNR Am J Neuroradiol 35:2302-2305, 2014

8. Clatterbuck RE, Elmací I, Rigamonti D: The juxtaposition of a capillary telangiectasia, cavernous malformation, and developmental venous anomaly in the brainstem of a single patient: case report. Neurosurgery 49:1246-1250, 2001

9. El-Koussy M, Schroth G, Gralla J, Brekenfeld C, Andres RH, Jung S, et al: Susceptibility-weighted MR imaging for diagnosis of capillary telangiectasia of the brain. AJNR Am J Neuroradiol 33:715-720, 2012

10. Finkenzeller T, Fellner FA, Trenkler J, Schreyer A, Fellner $\mathrm{C}$ : Capillary telangiectasias of the pons. Does diffusionweighted MR increase diagnostic accuracy? Eur J Radiol 74:e112-e116, 2010

11. Gross BA, Lin N, Du R, Day AL: The natural history of intracranial cavernous malformations. Neurosurg Focus 30(6):E24, 2011

12. Gross BA, Puri AS, Popp AJ, Du R: Cerebral capillary telangiectasias: a meta-analysis and review of the literature. Neurosurg Rev 36:187-194, 2013

13. Huddle DC, Chaloupka JC, Sehgal V: Clinically aggressive diffuse capillary telangiectasia of the brain stem: a clinical radiologic-pathologic case study. AJNR Am J Neuroradiol 20:1674-1677, 1999

14. Kiya K, Kitaoka T, Nomura M, Sato N, Naito M, Ohta M: Surgical evacuation of a pontine hematoma due to rupture of a capillary telangiectasis in a young patient-case report. Neurol Med Chir (Tokyo) 26:548-551, 1986

15. Kuzma B, Goodman JM, Britt P: Capillary telangiectasia of the pons. Surg Neurol 48:93-94, 1997

16. Lee RR, Becher MW, Benson ML, Rigamonti D: Brain capillary telangiectasia: MR imaging appearance and clinicohistopathologic findings. Radiology 205:797-805, 1997

17. Lerch KD, Schaefer D, Palleske H: Stereotactic microresection of small cerebral vascular malformations (SCVM). Acta Neurochir (Wien) 130:28-34, 1994

18. Lobato RD, Perez C, Rivas JJ, Cordobes F: Clinical, radiological, and pathological spectrum of angiographically occult intracranial vascular malformations. Analysis of 21 cases and review of the literature. J Neurosurg 68:518-531, 1988

19. McCormick PW, Spetzler RF, Johnson PC, Drayer BP: Cerebellar hemorrhage associated with capillary telangiectasia and venous angioma: a case report. Surg Neurol 39:451-457, 1993

20. Milandre L, Pellissier JF, Boudouresques G, Bonnefoi B, Ali Cherif A, Khalil R: Non-hereditary multiple telangiectasias of the central nervous system. Report of two clinicopathological cases. J Neurol Sci 82:291-304, 1987

21. Morinaka S, Hidaka A, Nagata H: Abrupt onset of sensorineural hearing loss and tinnitus in a patient with capillary telangiectasia of the pons. Ann Otol Rhinol Laryngol 111:855-859, 2002
22. Obrador S, Dierssen G, Odoriz BJ: Surgical evacuation of a pontine-medullary hematoma. Case report. J Neurosurg 33:82-84, 1970

23. Porter RW, Detwiler PW, Spetzler RF, Lawton MT, Baskin JJ, Derksen PT, et al: Cavernous malformations of the brainstem: experience with 100 patients. J Neurosurg 90:50-58, 1999

24. Pozzati E, Gaist G, Galassi E, Tognetti F: Giant cerebral capillary telangiectasis in an infant. Childs Brain 9:114-120, 1982

25. Pozzati E, Marliani AF, Zucchelli M, Foschini MP, Dall'Olio M, Lanzino G: The neurovascular triad: mixed cavernous, capillary, and venous malformations of the brainstem. J Neurosurg 107:1113-1119, 2007

26. Robinson JR Jr, Awad IA, Masaryk TJ, Estes ML: Pathological heterogeneity of angiographically occult vascular malformations of the brain. Neurosurgery 33:547-555, 1993

27. Sayama CM, Osborn AG, Chin SS, Couldwell WT: Capillary telangiectasias: clinical, radiographic, and histopathological features. Clinical article. J Neurosurg 113:709-714, 2010

28. Scaglione C, Salvi F, Riguzzi P, Vergelli M, Tassinari CA, Mascalchi M: Symptomatic unruptured capillary telangiectasia of the brain stem: report of three cases and review of the literature. J Neurol Neurosurg Psychiatry 71:390-393, 2001

29. Tang SC, Jeng JS, Liu HM, Yip PK: Diffuse capillary telangiectasia of the brain manifested as a slowly progressive course. Cerebrovasc Dis 15:140-142, 2003

30. Tomlinson FH, Houser OW, Scheithauer BW, Sundt TM Jr, Okazaki H, Parisi JE: Angiographically occult vascular malformations: a correlative study of features on magnetic resonance imaging and histological examination. Neurosurgery 34:792-800, 1994

\section{Disclosure}

The authors report no conflict of interest concerning the materials or methods used in this study or the findings specified in this paper.

\section{Author Contributions}

Conception and design: Zhao, Sun. Acquisition of data: Sun, You, Chen, JM Wang. Analysis and interpretation of data: Sun. Drafting the article: Sun. Reviewed submitted version of manuscript: Yu, Sun, Lin, Liang. Statistical analysis: Yu, Sun. Administrative/technical/material support: Yu, Sun. Study supervision: Sun, S Wang.

\section{Correspondence}

Jizong Zhao, Department of Neurosurgery, Beijing Tiantan Hospital, Capital Medical University, Tiantan Xili 6, Chongwen District, Beijing 100050, People's Republic of China. email: zhaojizong6@163.com. 